\title{
Climate Change Reporting \\ by Broadcast \\ Meteorologists
}

Adapted From "Reporting on

Climate Change by Broadcast

Meteorologists: A National

Assessment," by K. Timm (George

Mason University), D. Perkins,

T. Myers, B. Woods Placky, and

E. W. Maibach. Published online in

$B A M S$, February 2020. For the full, citable article, see: DOI:10.1175

/BAMS-D-18-0225.1.
W eathercasters can play an important role in society by helping viewers link day-to-day local weather experiences to information about broader, long-term climate trends. Until recently, however, few weathercasters reported about climate change on air. Many of them were once skeptical of human-caused climate change. They also perceived low levels of agreement among the climate science community, mistrusted climate models, or did not see climate change reporting as part of their professional role. Weathercasters felt they did not have time to prepare or present climate change stories and lacked access to climate scientists and easy-to-use content. Barriers included actual or anticipated lack of support from station management. Additionally, there was a fear of negative feedback from viewers. Some weathercasters avoided climate change reporting to stay out of broader conflict within their professional community on the topic.

Over the past decade, however, weathercatsers' understanding of climate change has evolved rapidly; they are now more aware of the scientific consensus that climate change is happening and is primarily anthropogenic. Reporting resources such as Climate Matters are freely available to simplify training and climate change story preparation. There are indications that organizational barriers are also being reduced. 
Climate change reporting has also evolved. Early studies described how weathercasters used community outreach presentations and the 15-20-second transitions between the news and weather to discuss climate change. In the 2000s, station websites and weathercaster blogs hosted climate change reporting. Weathercasters now also include climate change information in their on-air forecast, longer news stories, and social media. Weathercasters often refer explicitly to climate change; some present historical trends (e.g., in temperatures), but omit the phrase "climate change" or "global warming."

With support from the National Science Foundation, between 2015 and 2017 we conducted the most comprehensive surveys to date of broadcast meteorology professionals. These annual surveys assess weathercasters' views about climate change, climate change reporting, and the barriers they face in this reporting.

\section{Methods}

We identified and surveyed every person working in broadcast meteorology in the United States (based on a commercial database of news professionals, which we verified and updated manually by looking at websites for broadcast affiliates). Our first survey, conducted from 20 January through 23 February 2015 , had a response rate of $22.6 \%(\mathrm{~N}=466)$. Our second survey, 6 to 31 January 2016, had a response rate of $31.2 \%(\mathrm{~N}=629)$. Our final survey, 9 to 27 January 2017, had a response rate of $22.0 \%(\mathrm{~N}=480)$.

Participation rates were respectable considering the challenges of surveying news professionals. However, comparing participants

\section{Comfort Presenting Climate Change Topics On Air}

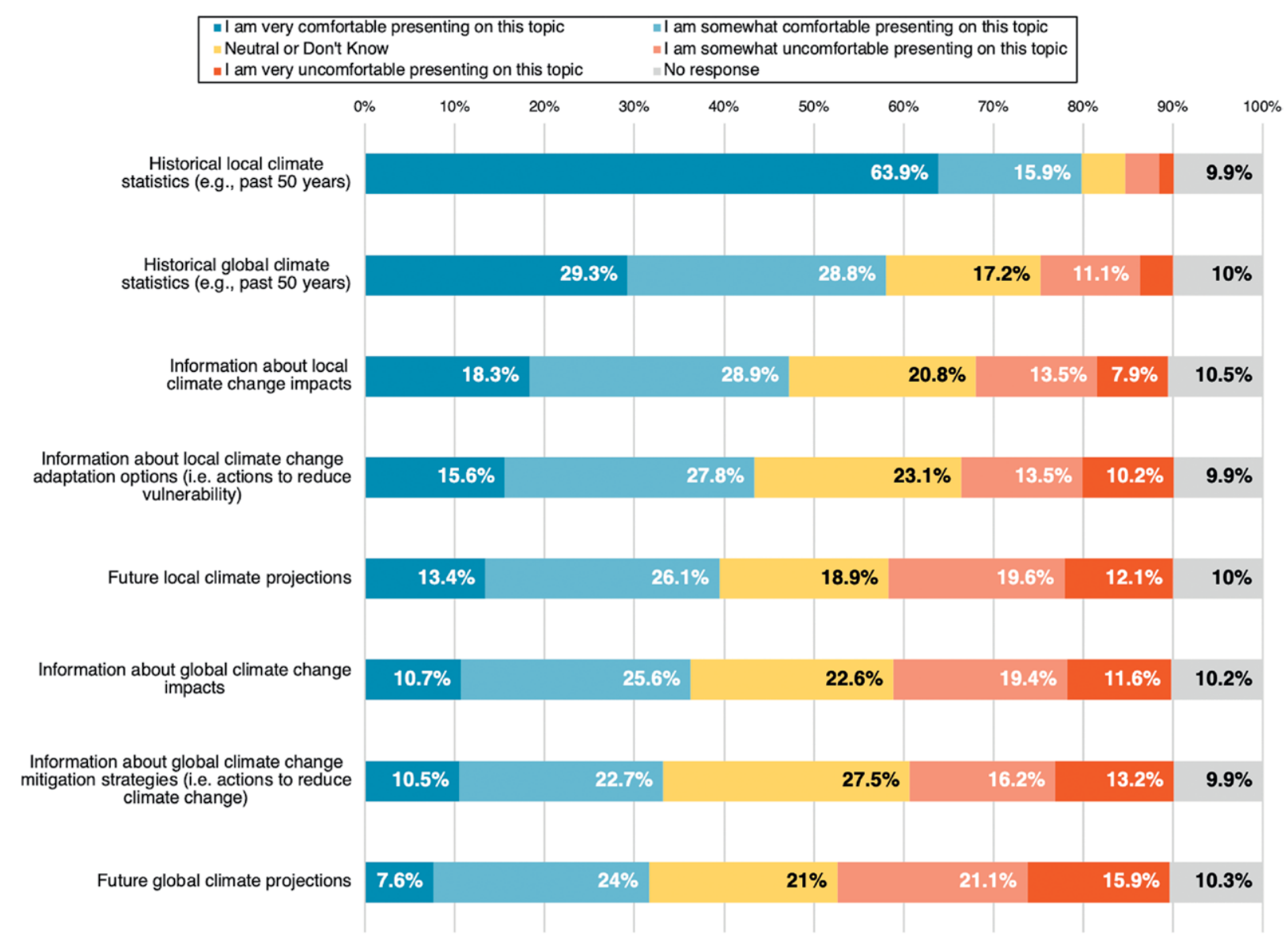

"How comfortable or uncomfortable are you (or would you be) in presenting the following kinds of materials to your viewers on air? 2016 National Survey of Broadcast Meteorologists $(N=629)$

Data labels are not pictured for amounts less than $5 \%$. 
and nonparticipants using publicly available data, we found that females were underrepresented in the survey and chief meteorologists were overrepresented. Weather anchors and people in the "other" category (meteorologists, weather producers, reporters, and temporary/fill-in meteorologists and weathercasters) were also underrepresented. Participants and nonparticipants did not differ in terms of geographic region, media market population size, economic situation, average temperature, or political ideology. The age of weathercasters surveyed did not vary much from year to year.

Our questions included a review of professional practices and pressures, views of climate change, climate change reporting interests and practices, and professional development needs. Certain questions varied from year to year. Median completion time was less than 20 minutes, and participants were sent up to 6 e-mail reminders to participate.

Across all three years, the largest segments of survey participants identified as chief meteorologists, weekend meteorologists, or morning/noon/midday meteorologists. The majority of survey participants possessed a bachelor's or masters degree in meteorology or atmospheric science. Additionally, many survey participants had a certificate in meteorology or broadcast meteorology, or a bachelor's degree in journalism or mass communication. About

\section{Methods Used to Share Local Climate Change Information}

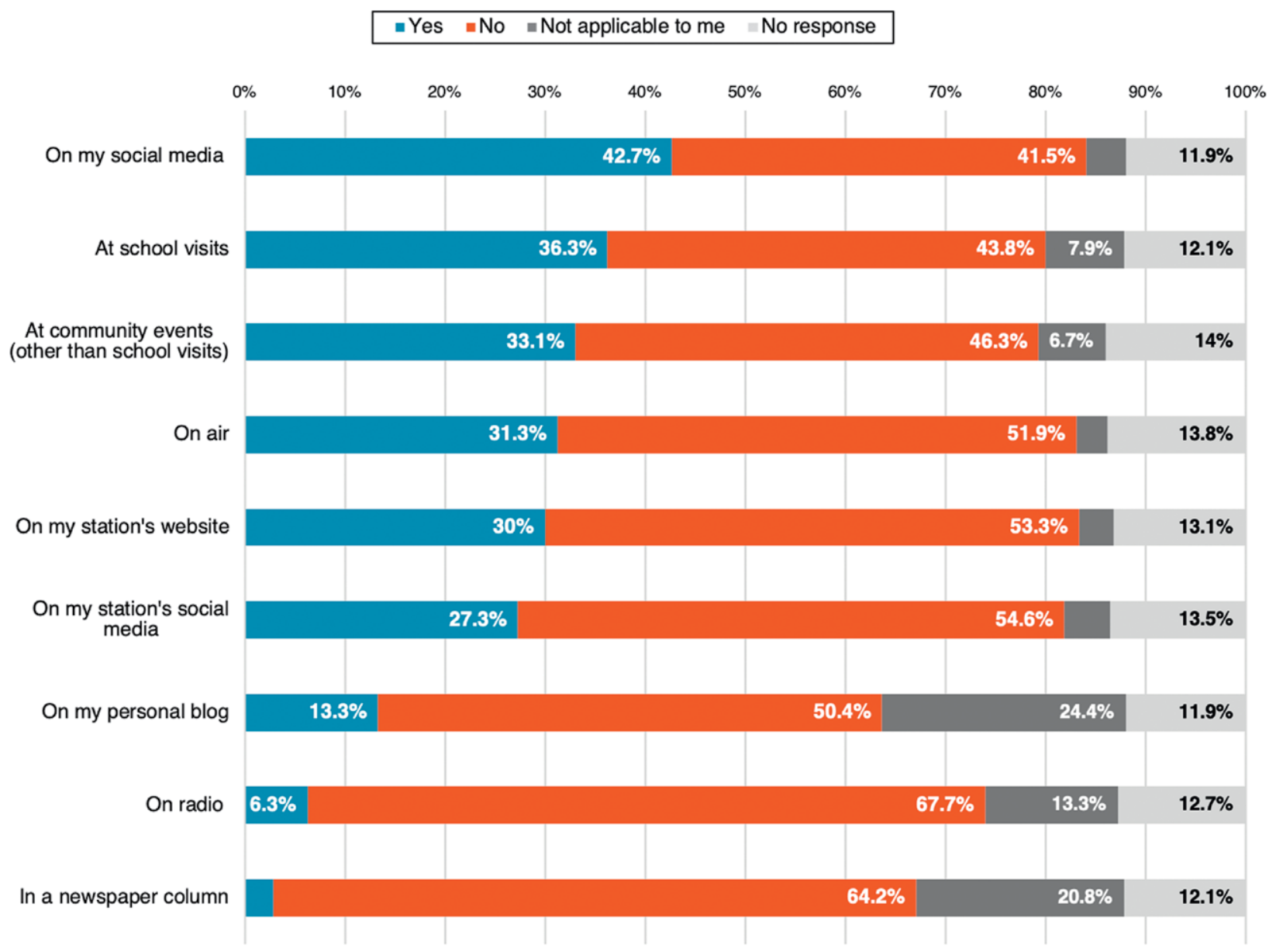

"Over the past 12 months, did you use the following channels to inform your viewers, or other people in your community, about the local impacts of climate change?"

2017 National Survey of Broadcast Meteorologists $(N=480)$

Data labels are not pictured for amounts less than $5 \%$. 
one-quarter of the respondents were AMS Certified Broadcast Meteorologists, another quarter had the AMS Seal of Approval, another quarter had no seal of approval, and around one-quarter had the National Weather Association (NWA) Seal of Approval.

\section{The state of climate change in broadcasting}

The AMS's "station scientist" initiative encourages broadcast meteorologists to cover a range of science beyond the weather, such as space and astronomy, climate, health, or energy. As of 2017, most weathercasters were aware of the initiative and were filling this role to some extent. Nonetheless, we provided a brief description: about one-third of these survey participants indicated that they would be interested in filling this role at their station.

More than half of weathercasters surveyed in 2015 said they were interested in presenting climate change topics that have broad, regional relevance, including extreme precipitation and/or flooding, drought and water shortages, extreme heat events, and impacts on plants and animals. Weathercasters expressed less interest in reporting on more regionally specific topics such as hurricanes, sea level rise, and wildfires.

A majority of survey participants indicated they were very comfortable presenting historical local climate statistics (63.9\%). Weathercasters, however, were least comfortable presenting information about global climate change mitigation strategies $(13.2 \%$ indicated very uncomfortable) and future global climate change projections $(15.9 \%)$ on air.

Similarly, in 2017, more than half $(56 \%)$ of the weathercasters surveyed were moderately or very interested in presenting local historical climate information from recent decades on air, while approximately one-third were interested in reporting about climate change impacts, adaptation efforts, protective behaviors, mitigation efforts, and future projections.

In 2017, nearly half of weathercasters (44.3\%) were somewhat, moderately, or very interested in reporting longer-format climate change stories on air outside of the weather segment. However, only about one-quarter (27.6\%) said they had done so in the past year.

In 2017, just more than half (57.9\%) of the weathercasters surveyed had informed their viewers or others in their communities about the local impacts of climate change at least one time in the prior year. Climate change information was most likely to be shared on social media (42.7\%), during in-person school (36.3\%) and community events (33.1\%), and during on-air broadcasts (31.3\%)

More than half $(58.6 \%)$ of the weathercasters who reported about local impacts of climate change on air did so one to four times in the past year. Not surprisingly, communicating with audiences online and on social media is increasingly common for weathercasters.

In 2017, we asked weathercasters what kind of audience feedback they had received when they reported on local climate change topics. More than one-quarter (28.6\%) of these weathercasters who had done so in the past year $(\mathrm{N}=150)$ received "very few reactions either way." However, of those receiving feedback, about one-third indicated that they received mixed but leaning positive or mostly positive feedback from their audiences. About one-quarter said the feedback was equally mixed between negative and positive, while only $12.2 \%$ said feedback was leaning or mostly negative.

We asked those who had not previously reported on local climate change topics what kind of feedback they expected to receive. In contrast to the mostly positive experiences of weathercasters who had reported on air about climate change, most weathercasters who had not reported local climate change topics on air believed that viewer feedback would be mostly negative. Almost half (44.2\%) expected negative feedback, and relatively few (11.2\%) believed they would get positive feedback.

\section{Suggestions for future surveys}

One limitation of the results is that our survey did not specify precisely what constitutes a "climate change news story" or "reporting on climate change." In the survey, we asked weathercasters if they had informed their viewers, or other people in their community, about the local impacts of climate change and if they had reported "on the local impacts of climate change." Unfortunately, there is no way to know exactly how survey participants interpreted these questions. In future surveys related to this topic, it would be valuable to provide a definition of climate change reporting 
specific to different media. For example, climate change reporting may be defined as one Facebook post that discusses the local effects of climate change. On air, it could be defined as any discussion about the local effects of climate change anywhere within the broadcast news program. Furthermore, it would be valuable to specify whether climate change reporting must include the words "climate change" or if any discussion about warming trends should also be considered reporting on climate change.

In addition to investigating climate change reporting across different communication methods, future research should also investigate the types of information weathercasters are presenting. For example, Climate Matters presents impacts of global climate change on local and regional weather, health, agriculture, water resources, and other interests. This local-story approach should help viewers see how climate change affects their own communities, is connected to their own experiences, and thus is personally relevant.

Finally, our survey has always been fielded in January or February. In 2015, we asked about interest in reporting about climate change impacts; the responses may have been affected by the weather of the prior year, and in fact, 2014 in the United States was notable for drought and heat, less so for large hurricanes.

A growing number of weathercasters are adopting the role of climate change educator. In doing so, they are finding a variety of ways to communicate about the changing weather and climate change in their local communities and regions, and likely helping their audiences understand more about this important issue.

\section{When you report about local climate change topics on air, is the feedback you receive from viewers...}

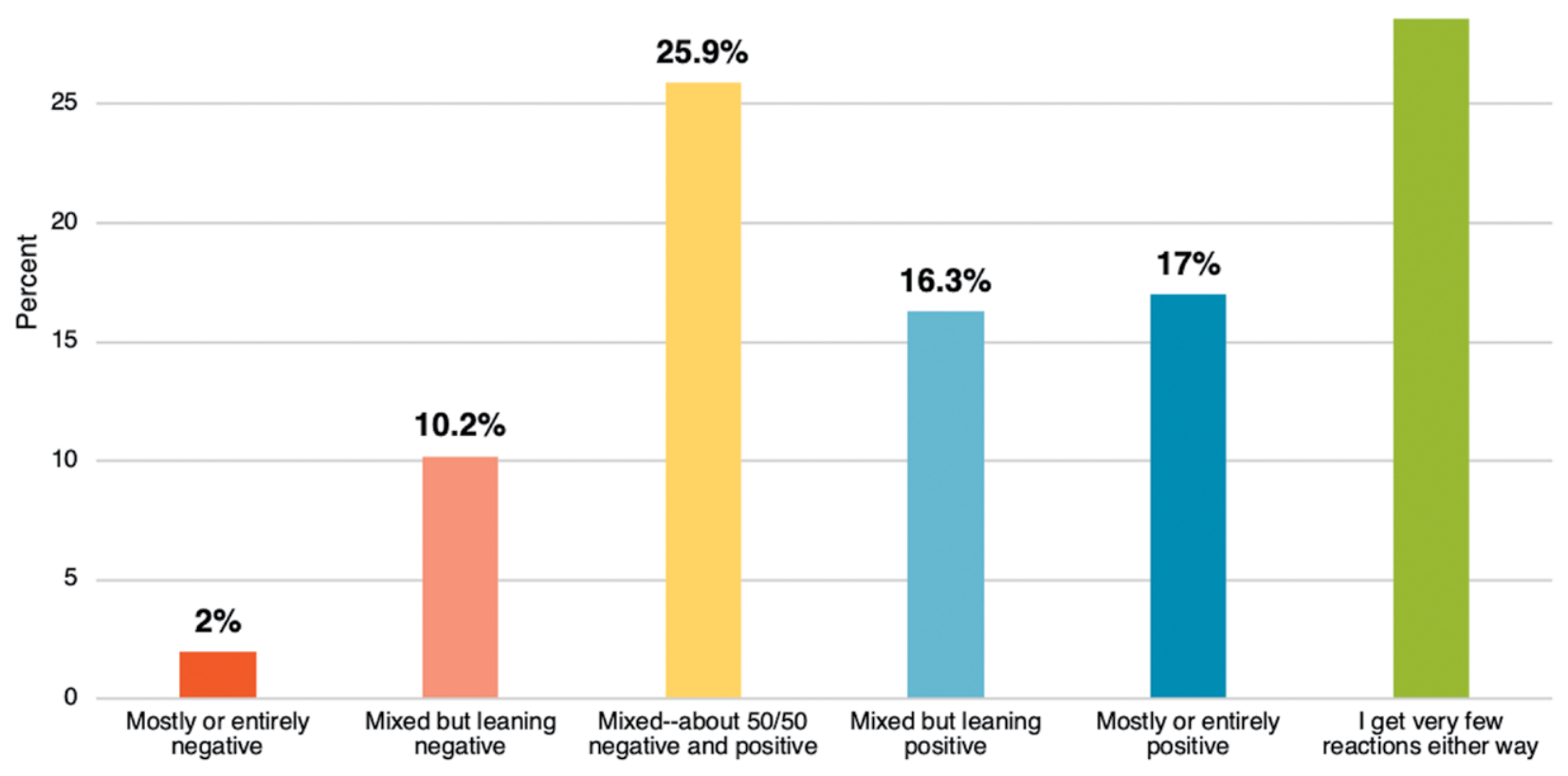

2017 National Survey of Broadcast Meteorologists $(N=150)$

Note: This question was administered to only people who said "Yes" they had presented "On air" in the question, "Over the past 12 months, did you use the following channels to inform your viewers, or other people in your community, about the local impacts of climate change?" 
BAMS: What would you like readers to learn from this article?

Edward W. Maibach: The community of broadcast meteorologists in the United States has changed rather dramatically over the past decade. In 2010, they really weren't playing much of a role in helping Americans understand the clear and present impacts of climate change on our lives. A mere five to seven years later, large numbers of them had recognized the opportunity to serve their community in this way and were successfully rising to the challenge. Being in close contact with the broadcast meteorology community in that time has enabled me to see this rapid evolution with my own eyes.

BAMS: How did you get involved in that evolution?

EWM: In 2008, Anthony Leiserowitz, Connie Roser-Renouf, and I conducted our first poll to explore public understanding of climate change. One of the important findings was that most members of the public trust $T V$ weathercasters as a source of information about global warming. Joe Witte, a senior broadcast meteorologist, saw those findings, called me up and said, essentially, "Hey, this is important. Perhaps we weathercasters can help educate Americans about the local relevance of global climate change." That conversation gave rise to research with TV weathercasters, which eventually led to the creation of Climate Matters (with Climate Central).

Kristin Timm: I was working with scientists to communicate climate change research to different audiences. I had started looking for studies to inform my practice, and that is when I learned about Ed's work. When I decided to pursue a Ph.D., I knew I wanted to work with a team that was using research to improve climate change communication in practice. When Ed asked if I would like to work on this project with TV weathercasters, I jumped at the opportunity.

BAMS: What was the biggest challenge you encountered while doing this work?

KT: Making sure enough people respond to the survey so that we could be confident in the results. Email surveys are frustrating because you never know if the survey wasn't answered because the email went into a spam filter, was deleted, or the person didn't have time or want to respond.

BAMS: Either way, that's a very different response problem than a decade ago...

EWM: Early on-especially when were conducting our first survey of broadcast meteorologists-a handful of skeptical weathercasters distrusted me and doubted my motives. One even confronted me in the middle of an AMS broadcast meeting session demanding to know "my agenda." By explaining, when asked, that my only agenda is to help interested members of the broadcast meteorology community share with their audience what is known about our changing climate, the distrust and resistance evaporated rather quickly.

BAMS: This new survey helps confirm such changes over such a short time. Were you surprised by the findings?

EWM: Not by our findings, perse.

KT: I was most surprised to learn how TV weathercasters who are reporting about climate change versus those who are not have vastly different perceptions of how the audience will respond to that information. I remain curious about whether the audiences of those markets are significantly different or if something else is influencing TV weathercasters' perceptions of their audience.

BAMS: What other valuable findings do you see?

EWM: The surveys reveal lots of important detail on how broadcasters' attitudes were changing, and on how our Climate Matters team could continue to support those changes-which to me is the most important outcome of this research. 